\title{
Tumor Cell Lysate Vaccine Therapy
}

National Cancer Institute

\section{Source}

National Cancer Institute. Tumor Cell Lysate Vaccine Therapy. NCI Thesaurus. Code C116546.

A method by which dendritic cells are pulsed in vitro with tumor cell lysate to induce maturation with the purpose of inducing a targeted immune system response against the tumor. 